\title{
FINANCE AND BALANCED GROWTH
}

\author{
Alex Trew \\ University of St. Andrews
}

We study the relationships between various concepts of financial development and balanced economic growth. A model of endogenous growth that incorporates roles for both financial efficiency and access to financial services permits a better understanding of the relationship between the size of the financial sector (value added) and growth. Higher financial value added results from some, but not all, kinds of finance-driven growth. If greater access rather than greater efficiency generates higher growth, then value added and growth can be positively correlated. We present some preliminary empirical results that support the importance of access alongside efficiency in explaining cross-country variations in growth.

Keywords: Finance and Growth, Endogenous Growth, Uzawa Theorem

\section{INTRODUCTION}

The literature on the relationship between financial development and economic growth has become one of the most important in applied economics. The early empirical work of King and Levine (1993a, 1993b) found that financial depth-the size of the financial sector as a proportion of output - is an important explanation for variations in growth across countries. The robustness of that connection has been supported by subsequent studies such as Demirgüç-Kunt and Maksimovic (1998), Levine et al. (2000), and Rousseau and Sylla (2005). ${ }^{1}$ Although the argument that finance can matter for growth is well established, important variations have been found in the significance and direction of the finance-growth connection across countries [Demetriades and Hussein (1996)], across stages of development [Rioja and Valev (2004)], and across time [Rousseau and Wachtel (2011)].

The empirical link between financial development and growth has been supported by the emergence of a theoretical literature on financial intermediation and endogenous growth. Works such as King and Levine (1993b), de la Fuente and Marín (1996), Blackburn and Hung (1998), Khan (2001), Aghion et al. (2005), and Horri et al. (in press) offer a large number of ways in which financial

I am grateful to an associate editor and two referees for comments that greatly improved the paper. I also thank seminar participants at Edinburgh, Leicester, Newcastle, Oxford and St Andrews, and, without implication, in particular to Charles Nolan and Panicos Demetriades for helpful discussions. Finally, I am grateful to Jukka-Pekka Soikkeli for excellent research assistance. Address correspondence to: Alex Trew, School of Economics and Finance, University of St. Andrews, St. Andrews, Fife, UK, KY16 9AL; e-mail: alex.trew@st-andrews.ac.uk; URL: http:// www.st-andrews.ac.uk/ awt2. 
efficiency - the costs of screening entrepreneurs, monitoring effort, providing liquidity insurance, and so on-can impact the equilibrium rate of technological progress and thus long-run growth. ${ }^{2}$ More recently, Laeven et al. (2009) and Greenwood et al. (2010) have looked to incorporate endogenous financial innovation into models of growth.

This theoretical focus on the efficiency of intermediation has been driven by the dependence of endogenous growth models on the production of new ideas and technologies. The complementarity between the empirical and theoretical findings thus rests upon the implicit assumption that efficiency and depth are both good proxies for the financial development that matters for economic growth in the long run.

This paper contributes to the theoretical literature on finance and growth by developing simple models that can capture the connections between different concepts of financial development when the economy is growing in the long run. Doing so suggests ways to understand some of the more nuanced relationships between finance and growth observed in the data and points in a number of directions for future empirical research.

First, a simple neoclassical growth model demonstrates that balanced growth restricts how financial efficiency is related to the quantity of financial services (financial value added). Incorporating financial efficiency alone is not sufficient to understand why the size of the financial sector might be positively related to growth. This is because value added must be constant along the balanced-growth path (BGP); when the long-run growth rate changes, value added and growth are negatively related. To understand the implications of this, we second develop an endogenous growth model that is extended to account for differences in access to finance. This permits us to see how a positive relationship between value added and the growth rate can emerge. Specifically, if finance-led growth results mainly from improvements in access, then higher growth can be associated with higher financial value added; if it results from greater financial efficiency, then the correlation between value added and growth can be zero or even negative. The theoretical importance of access can be related to aspects of models such as those of Greenwood and Jovanovic (1990) and Rousseau (1998). The contribution of this paper is in bringing together different concepts of financial development in a simple model of growth with direct implications for the empirical literature. The role for access also gives weight to a recent literature [see Beck and DemirgüçKunt (2008)] that stresses access to finance as a policy tool.

The endogenous growth model has two main implications for the empirical assessment of the finance-growth nexus. The first is that a focus on the size of the financial sector alone is not a reliable indicator of growth-promoting financial development. The findings noted previously that the finance-growth connection has weakened over time or is dependent on the stage of development are consistent with this theoretical implication, but a proper test would require more data on access than are currently available. The second implication is that access and efficiency are the key parts of the finance-growth mechanism, and so should be 
considered alongside size in growth regressions. New data on access in Kendall et al. (2010) present an opportunity to consider the role of access in supplementing the earlier finance and growth regressions. We present some regression results that include proxies for efficiency, access, and financial depth. We find an important role for access and efficiency, but none for financial depth.

The rest of the paper is outlined as follows. Section 2 develops the simple neoclassical model with a role for financial efficiency in determining the level of technological progress. Section 3 presents the model of endogenous growth, first without considering access to finance. Using the model with access, we develop the implications for the relationship between long-run growth and financial efficiency, value added, and access. Section 4 presents growth regressions that include proxies for all three theoretical concepts of financial development. Section 5 offers some concluding remarks.

\section{BALANCED GROWTH AND FINANCE}

Consider the neoclassical production function

$$
Y_{t}=F\left[K_{t}, L_{t}, A_{t}\left(\zeta_{t}\right)\right]
$$

where capital, $K_{t}$, and labor, $L_{t}$, combine with a measure of technological progress, $A_{t}$, to produce output and where $F(\cdot)$ has the usual characteristics, including linear homogeneity. The parameter $\zeta_{t}$ denotes financial efficiency, which enters as an input to the level of technological progress. In theoretical analyses of finance and growth, something like $\zeta_{t}$ is generally the object of interest. Exactly how it represents financial matters and how it enters into $A_{t}$ can vary; for the purposes of this model, we simply assert that greater financial efficiency increases the level of technology, $A^{\prime}>0$.

Typically not modeled are the costs associated with that financial efficiency. Financial intermediary services provide, for example, specialized screening of entrepreneurs of unknown type at a cost that reflects the efficiency of finance. When firms pay those financial intermediaries, they allocate resources away from investment or production. Financial value added is then the sum of such costs as a proportion of aggregate output. When financial efficiency changes, the costs of intermediation change and so the sum of resources going to financial services can also change; that is, financial efficiency, financial value added, and the level of technological progress are all connected.

Financial value added thus defined enters into the capital accumulation equation as follows,

$$
\dot{K}_{t}=Y_{t}-C_{t}-D\left(\zeta_{t}\right) Y_{t}-\delta K_{t},
$$

where $\delta>0$ is the depreciation rate, $D\left(\zeta_{t}\right)$ is financial value added based on the costs of financial services, and there are no a priori assumptions about $D^{\prime} .^{3}$

The economy is on a BGP if and only if output, capital, consumption, and value added are all positive and all grow at constant exponential rates $g_{y}, g_{k}, g_{c}$, and $g_{d}$, 
respectively, for all $t \geq 0$ :

$$
\begin{aligned}
Y_{t} & =Y_{0} e^{g_{y} t}, \\
K_{t} & =K_{0} e^{g_{k} t}, \\
C_{t} & =C_{0} e^{g_{c} t}, \\
D_{t} & =D_{0} e^{g_{d} t},
\end{aligned}
$$

where $D_{t}$ is shorthand for $D\left(\zeta_{t}\right)$. Assume that there is no growth in the labor supply: $L_{t}=L$ for all $t \geq 0$. The first part of Proposition 1 makes clear that if financial value added is related to financial efficiency, then improvements in financial efficiency cannot be related to improvements in technology.

PROPOSITION 1. On the BGP, (i) financial efficiency cannot be related to sustained technological progress unless it does not interact with financial value added; and (ii) if financial efficiency is related to long-run technological change without interacting with value added, it must be labor-augmenting.

Proof. The proof uses a variant of that of the Uzawa (1961) theorem found in Schlicht (2006). ${ }^{4}$ We can rewrite (2) for $t \geq 0$, using the definition of a BGP:

$$
\left(\delta+g_{k}\right) K_{0}=e^{\left(g_{y}-g_{k}\right) t} Y_{0}-e^{\left(g_{y}+g_{d}-g_{k}\right) t} Y_{0} D_{0}-e^{\left(g_{c}-g_{k}\right) t} C_{0} .
$$

Taking the derivative of (7) with respect to time, we can see that on a BGP,

$$
\begin{aligned}
0 & =\left(g_{y}-g_{k}\right) e^{\left(g_{y}-g_{k}\right) t} Y_{0}-\left(g_{y}+g_{d}-g_{k}\right) e^{\left(g_{y}+g_{d}-g_{k}\right) t} Y_{0} D_{0} \\
& -\left(g_{c}-g_{k}\right) e^{\left(g_{c}-g_{k}\right) t} C_{0} .
\end{aligned}
$$

If $g_{d}+g_{y}=g_{k}$, then it must be the case that $g_{y}=g_{c}$ and $\left(g_{y}-g_{k}\right)\left(Y_{0}-C_{0}\right)=0$, which cannot be true on a BGP, because it would imply that $K_{0}<0$. As such, we must have that $D_{0}>0, g_{d}=0$, and $g_{c}=g_{y}=g_{k} \geq 0$.

Assume that technology $A_{t}$ augments one or both of the factors of production with coefficients of technological progress $A_{K, t}$ and $A_{L, t}$. Then let $G\left(A_{K, t} K_{t}, A_{L, t} L_{t}\right):=F(\cdot)$. Using homogeneity of the production function, we can write

$$
Y_{t}=G\left(e^{\left(g_{y}-g_{k}\right) t} K_{t}, e^{g_{y} t} L\right), \text { for any } t \geq 0 .
$$

Because $g_{y}=g_{k}$, equation (9) shows that all technological progress, $\dot{A}_{t} / A_{t}=g_{y}$, is purely labor-augmenting.

If $D^{\prime} \neq 0$, part (i) of the proposition follows from the BGP requirement that $g_{d}=0$. If $D^{\prime}=0$, part (ii) follows from the requirement that technological progress, including that due to financial efficiency, be Harrod-neutral on BGPs.

The proposition has two main implications, one for the relationship between financial efficiency and value added in an economy on a BGP, and another for the relationship between financial efficiency and technological progress in balanced 
growth. Sustained progress in financial efficiency can only be part of technological change if, first, financial efficiency does not affect financial value added and, second, it is labor-augmenting. Both of these requirements might be considered somewhat restrictive. Either way, the implication for financial value added is clear: Away from a BGP, value added can vary, but in the long run it must be constant. Sections 3 elaborates on the first of these two implications in the context of an endogenous growth model. That generates a number of insights, some of which are addressed in the empirical analysis of Section 4. The more general implications of labor-augmenting technological change for finance and growth are left for future research.

\section{FINANCE AND ENDOGENOUS GROWTH}

In models of endogenous growth where financial efficiency matters, intermediaries exist to screen potential entrepreneurs, to monitor research effort, or to evaluate the quality of discoveries; that is, they intermediate between those who wish to acquire new technologies or blueprints for intermediate goods and those who have the ideas for those new technologies or blueprints. ${ }^{5}$ The expanding inputs model expounded in Acemoglu (2009) serves as a useful framework within which to explore the balanced growth connections between finance and growth. We adapt that model to include a simple screening problem with which the intermediary can be engaged. Other features of the model are standard, so we leave some details to Acemoglu (2009).

\subsection{Preferences and Technology}

The representative household has constant intertemporal elasticity of substitution (CIES) preferences, choosing consumption levels to maximize the present value of discounted future utility,

$$
\int_{0}^{\infty} e^{-\rho t}\left(\frac{C_{t}^{1-\theta}-1}{1-\theta}\right) d t
$$

where $\rho>0$ is the discount rate of the household and $\theta \geq 0$ is the coefficient of relative risk aversion.

Agents consume a perfectly competitive final good, $Y_{t}$, the price of which is normalized to one at each date. The production of the final good takes a DixitStiglitz form and uses labor, $L$, and a variety of machines, $x_{t}$, as inputs,

$$
Y_{t}=\frac{1}{1-\beta}\left[\int_{0}^{N_{t}} x_{t}(v)^{1-\beta} d v\right] L^{\beta},
$$

where $v$ indexes input variety and $N_{t}$ is the total number of machine input varieties in existence at time $t$. The number $N_{t}$ is thus our measure of technological progress. The machines used as inputs to final good production are supplied by the holders of blueprints for those machines. The discovery of new blueprints requires 
investment, $Z_{t}$, in laboratory equipment. Where $X_{t}$ is the total spent on machines at $t$, the economywide resource constraint is

$$
Y_{t} \geq C_{t}+X_{t}+Z_{t}
$$

\subsection{Technological Progress and Finance}

Some of the investment in laboratory equipment is dedicated to financial intermediation of the King and Levine (1993b) type. Laboratory equipment can itself be of different levels of quality: Capable (incapable) scientists have created good (bad) laboratory equipment. A proportion $\phi \in(0,1)$ of scientists are capable; the remaining $(1-\phi)$ are not. Only by investing in the good equipment, that created by capable scientists, can new blueprints be discovered.

Machine producers can see who created what equipment, but it is infinitely costly for them to see the type of scientist. Financial intermediaries exist to reveal type by charging a fee for screening potential researchers. The screening mechanism is perfect (the truth is always known, postscreen), but the efficiency of the screening, $\zeta_{t}$, determines its cost. ${ }^{6}$ For a given $\zeta_{t}$, the evolution of new blueprints then follows

$$
\dot{N}_{t}=\eta_{N} Z_{t}\left[1-f\left(\zeta_{t}\right)\right],
$$

where $\eta_{N}>0$ and $f\left(\zeta_{t}\right)$ is the fee charged for intermediation, expressed in units of laboratory equipment invested. ${ }^{7}$ The efficiency level $\zeta_{t}$ is exogenous but not necessarily constant over time. The quantity of financial services as a proportion of total output (financial value added) is then

$$
\mathcal{D}_{t}=\frac{f\left(\zeta_{t}\right) Z_{t}}{Y_{t}} .
$$

The fee charged is based on the screening problem faced by the intermediary. Intermediaries face a cost $z\left(\zeta_{t}\right)>0$ of screening scientists from the pool of applicants, where $z^{\prime}<0$. An intermediary chooses the fee that maximizes expected profits from providing screening services,

$$
E[\text { profit }]=\phi\left[f Z_{t}-z\left(\zeta_{t}\right)\right]+(1-\phi)\left[-z\left(\zeta_{t}\right)\right] .
$$

Assuming competitive intermediation, the fee charged is simply

$$
f^{*}\left(\zeta_{t}\right)=\frac{z\left(\zeta_{t}\right)}{\phi Z_{t}}
$$

Evidently, an increase in financial efficiency will, other things being equal, reduce the fee charged for intermediation, increase the rate of discovery of new blueprints, and decrease the level of financial value added. Despite running counter to evidence, this is intuitive in a setup where financial intermediaries do nothing other than funnel research funding to the right research activities. As such, this implication is consistent with other finance and endogenous growth models, and 
Section 3.5 shows that reconciling the correlation between efficiency and value added with data requires us to modify the model only slightly.

\subsection{Equilibrium and the Balanced Growth Path}

Profit maximization by the final goods producer yields the demands for machines

$$
x_{t}(v)=p_{t}^{x}(v)^{-1 / \beta} L,
$$

where $p_{t}^{x}$ is the machine price set by the blueprint holder.

Let $\pi_{t}(v) \equiv p_{t}^{x}(v) x_{t}(v)-\psi x_{t}(v)$ be the instantaneous profits which accrue from selling machine variety $v$ at time $t$. Given that the blueprint owner is a monopolist in producing the machine variety, the price $p_{t}^{x}(v)$ is chosen to maximize $\pi_{t}(v)$. Because the demand for machines is isoelastic, the price $p_{t}^{x}(v)$ is invariant across time and machine variety so we normalize the marginal cost of machine production to $\psi=(1-\beta)$. As such, the profit-maximizing price is $p_{t}^{x}(v)=1$ and monopoly profits are $\pi_{t}(v)=\beta L$. The final good production function can then be written as

$$
Y_{t}=\frac{1}{1-\beta} N_{t} L .
$$

Equation (18) implies that any balanced growth equilibrium where $Y_{t}$ grows at a constant rate will also have $N_{t}$ growing at a constant rate.

The net present discounted value of a perpetual license to a blueprint can be written as

$$
V_{t}(v)=\frac{\pi_{t}(v)+\dot{V}_{t}(v)}{r_{t}},
$$

where $r_{t}$ is the interest rate and $\dot{V}_{t}(v)$ is the change in the net present value of a blueprint over time [see Acemoglu (2009)].

When there is positive technological progress, free entry to research requires that one unit of spending on equipment leads to an equal net present discounted return to the blueprint holder,

$$
\left[1-f^{*}\left(\zeta_{t}\right)\right] \eta_{N} V_{t}(v)=1
$$

An economy on a BGP is one in which the growth rate of output (and consumption) is constant. Consumer optimization yields

$$
g_{c}=\frac{\dot{C}_{t}}{C_{t}}=\frac{1}{\theta}\left(r_{t}-\rho\right) .
$$

This Euler equation implies that a BGP is characterized by a constant interest rate. Because profits on blueprint ownership are also constant over time, it must be the case that $\dot{V}_{t}(v)=0$. When this is combined with equations (19) and (20), the equilibrium interest rate along a BGP is

$$
r^{*}=\left[1-f^{*}\left(\zeta_{t}\right)\right] \eta_{N} \beta L,
$$


which makes the equilibrium balanced growth rate equal to

$$
g^{*}=\theta^{-1}\left\{\left[1-f^{*}\left(\zeta_{t}\right)\right] \eta_{N} \beta L-\rho\right\} .
$$

Equation (23) implies that the higher the efficiency with which financial intermediaries screen scientists, the higher is the equilibrium growth rate.

\subsection{Financial Efficiency and Financial Value Added along the Balanced Growth Path}

A direct result of equation (18) is that along a BGP, $N_{t}$ must also grow at a constant rate $\dot{N}_{t} / N_{t}=g^{*}$. We then have

PROPOSITION 2. Financial value added is constant on a balanced growth equilibrium of the model.

Proof. The growth rate of new blueprints is

$$
\frac{\dot{N}_{t}}{N_{t}}=\frac{\eta_{N}\left[Z_{t}-z\left(\zeta_{t}\right) / \phi\right]}{N_{t}},
$$

which must be constant on a BGP. Because total spending on machines is $X_{t}=$ $(1-\beta) N_{t} L$, the BGP combined with the economywide resource constraint implies that the growth rate of $Z_{t}$ must be constant also, which is not possible unless $z\left(\zeta_{t}\right)$ is proportional to $Z_{t}$. With $z\left(\zeta_{t}\right)$ proportional to $Z_{t}$ and using equation (16), financial value added, equation (14), is a constant on a BGP.

Proposition 2 shows that a BGP requires that financial costs as a proportion of research spending, $z\left(\zeta_{t}\right) / Z_{t}$, are constant; that is, relative financial efficiency is constant. This can happen if $\zeta_{t}$ falls over time in such a way as to make $z\left(\zeta_{t}\right)$ increase along with $Z_{t}$, but it is more typical for something such as $\zeta_{t}$ itself to reflect that relative financial efficiency. Thus, let $z$ take the form

$$
z\left(\zeta_{t}\right)=\frac{\eta_{Z} Z_{t}}{\zeta_{t}}
$$

with $\eta_{Z}>0$. Then the optimal fee charged by intermediaries is constant on BGP: $f^{*}\left(\zeta_{t}\right)=\eta_{Z} /\left(\phi \zeta_{t}\right)^{8}$

This analysis provides a basis for the focus on relative financial efficiency found in the theoretical literature. ${ }^{9}$ It also gives an idea about what must be happening to financial value added along a BGP, because there is an implied relationship between value added and efficiency when the BGP itself changes. Suppose, for example, that relative financial efficiency increases. Because there are no transition dynamics, the rate of growth of output and consumption along the BGP immediately increases, but financial value added decreases-though consumption growth is faster, the resources allocated to finance as a proportion of output are smaller. 
The model as laid out so far suggests that it is not possible to have anything other than a negative relationship between efficiency and value added on the BGP. Though there has been evidence against the finance-growth nexus in some countries and some time periods, there remains strong evidence that size does matter in some countries, or has mattered over particular time periods. These variations in the measured connection between finance and growth require that a model of finance and growth should be able to account for both the presence and the absence of a role for the size of the financial sector in explaining variations in economic growth. Section 3.5 looks at what relaxations of the model are needed to understand this inconstancy.

\subsection{Access to Finance}

A number of models of finance and growth assume that a part of financial development can be an increase in the number of agents using financial services, in addition to an increase in the efficiency with which they do so. A simple exposition is Townsend (1983), where development can be characterized as a proportion of all nonfinanced agents being "thrown" into the financial sector at the start of each period. Additionally, Greenwood and Jovanovic (1990) model the relationship between inequality, growth, and the extent of financial development, and Acemoglu and Zilibotti (1997) model barriers to risk sharing that are progressively overcome through time.

Suppose that only some fraction $\lambda_{t} \in[0,1]$ of scientists are able to be screened, regardless of their type. The proportion $\lambda_{t}$ can affect both the cost of screening and the rate of new discoveries. First, the larger the pool of scientists (the higher is $\lambda_{t}$ ) among whom the intermediary screens, the more costly it is to screen out incapable scientists. ${ }^{10}$ The following formulation simply generalizes (25):

$$
z\left(\zeta_{t}, \lambda_{t}\right)=\frac{\lambda_{t} \eta_{Z} Z_{t}}{\zeta_{t}}
$$

Second, the rate of increase in new blueprints increases in the portion that have access to finance. So the evolution of blueprints follows

$$
\dot{N}_{t}=\lambda_{t} \eta_{N}\left(1-\frac{\lambda_{t} \eta_{Z}}{\phi \zeta_{t}}\right) Z_{t}
$$

and the balanced path rate of growth is

$$
g^{*}=\theta^{-1}\left[\lambda_{t} \eta_{N}\left(1-\frac{\lambda_{t} \eta_{Z}}{\phi \zeta_{t}}\right) \beta L-\rho\right] .
$$

As before, greater financial efficiency increases long-run growth. The impact of access on growth depends on whether the costs from greater screening are outweighed by the gains from the more rapid generation of ideas; i.e., if $\phi \zeta_{t}>$ $2 \lambda_{t} \eta_{Z}$, then greater access to finance increases long-run growth (and indeed this 
is necessary for positive growth). As already established, along a BGP, the ratio $Z_{t} / N_{t}$ is constant. The effect of an increase in financial efficiency is to speed up the rate of discovery of new blueprints; the effect of increasing access to financial services is ambiguous, however. Compared with the model where access is complete $\left(\lambda_{t}=1\right.$ for all $\left.t\right)$, the nature of financial development along the BGP can be very different. Suppose that access and efficiency can both change exogenously over time at rates $\dot{\lambda}_{t}$ and $\dot{\zeta}_{t}$, respectively. The BGP can then be characterized by

PROPOSITION 3. On the BGP, financial value added increases at a rate proportional to that at which access increases.

Proof. The BGP requires that $\dot{N}_{t} / N_{t}$ is constant, which implies that

$$
\left(1-\frac{2 \lambda_{t} \eta_{Z}}{\phi \zeta_{t}}\right) \dot{\lambda}_{t}=-\frac{\lambda_{t}^{2} \eta_{Z}}{\phi \zeta_{t}^{2}} \dot{\zeta}_{t}
$$

Financial value added is $\mathcal{D}_{t}=\lambda_{t} f\left(\zeta_{t}, \lambda_{t}\right) \varphi$, where $\varphi=Z_{t} / Y_{t}$ is the constant share of output allocated to research. Taking the derivative of value added with respect to time and using (29), the change of value added on the BGP is

$$
\dot{\mathcal{D}}_{t}=\varphi \dot{\lambda}_{t} .
$$

Financial value added can grow while the economy is on the BGP if $\dot{\lambda}_{t}>0$.

One solution to (29) is for the BGP to be characterized by no development in access or efficiency, $\dot{\zeta}_{t}=\dot{\lambda}_{t}=0$. However, it is possible to have some forms of financial development on BGP. If increasing access is growth-reducing (i.e., if $2 \lambda_{t} \eta_{Z}>\phi \zeta_{t}$ ), then it is possible to have $\dot{\zeta}_{t}>0$ and so $\dot{\lambda}_{t}>0$ on the BGP. In that case, value added and efficiency can both be increasing over time on a BGP. Clearly, there is a limit to this when access becomes high (i.e., close to $\lambda=1$ ).

What is the correlation between long-run growth and value added when access to finance can change? Suppose that financial efficiency and access both increase over time, and that they combine to increase growth by some $d>0$ :

$$
\left(1-\frac{2 \lambda_{t} \eta_{Z}}{\phi \zeta_{t}}\right) \dot{\lambda}_{t}+\frac{\lambda_{t}^{2} \eta_{Z}}{\phi \zeta_{t}^{2}} \dot{\zeta}_{t}=d>0
$$

If $2 \lambda_{t} \eta_{Z}<\phi \zeta_{t}$, equation (31) is the sum of the positive effects of increasing access and efficiency on growth. Using (31), the change in value added is simply

$$
\dot{\mathcal{D}}_{t}=\varphi\left(\dot{\lambda}_{t}-d\right)=\varphi \frac{\lambda_{t} \eta_{Z}}{\phi \zeta_{t}}\left(2 \dot{\lambda}_{t}-\frac{\lambda_{t}}{\zeta_{t}} \dot{\zeta}_{t}\right),
$$

which, using the expressions for value added, $\mathcal{D}_{t}=\lambda_{t} f\left(\zeta_{t}, \lambda_{t}\right) \varphi$, and equilibrium fee, $f\left(\zeta_{t}, \lambda_{t}\right)$, can be written as 


$$
\frac{\dot{\mathcal{D}}_{t}}{\mathcal{D}_{t}}=\varphi\left(2 \frac{\dot{\lambda}_{t}}{\lambda_{t}}-\frac{\dot{\zeta}_{t}}{\zeta_{t}}\right)
$$

Equation (32) gives the change in value added associated with higher long-run growth. If that higher growth is generated by greater access alone, then the correlation between value added and growth will be positive. If the higher growth comes from greater efficiency, however, this correlation can be negative.

To summarize, the model implies that greater financial efficiency will always generate higher growth; that greater access will benefit growth if the faster idea generation outweighs the greater screening costs; and that higher value added can be associated with higher growth if additional screening costs outweigh the additional idea generation and if access is the predominant source of finance-led growth.

\section{EMPIRICAL EVIDENCE}

The cross-country approach to understanding the empirical relationship between financial and economic development, after King and Levine (1993a,1993b), has concentrated on financial depth (the size of the financial sector as a proportion of national output) as a measure of financial development. Regressions of average rates of growth of GDP per capita on average levels of financial depth over the period 1960-1989 identified a positive and sometimes causal connection running from financial deepening to higher growth [see, e.g., Levine et al. (2000) and the survey in Levine (2005)].

The theoretical model in Section 3 tells us two things of relevance for the empirical study of finance and growth. The first is that the size of the financial sector may not be a reliable indicator of growth driven by finance. ${ }^{11}$ The specific theoretical implication of equation (32) is that only where higher growth is supported by increasing access to finance rather than by increasing financial efficiency would we observe a positive relationship between the size of the financial sector and growth. Current cross-country data on access do not permit this implication to be tested directly, but it is consistent with some extant empirical results. Rioja and Valev (2004) found that the level of development can matter for the strength of the impact of financial deepening on growth. If more developed countries already have wide access to financial services, then more financial development would come from greater efficiency and so the depth-growth connection would, according to equation (32), be lower. The same logic would apply to Hasan et al. (2009), which finds that the efficiency of financial intermediation dominates the quantity of credit in its importance for growth in an empirical study of European countries. Rousseau and Wachtel (2011) show that the impact of financial deepening on growth has diminished in the later twentieth century, a finding apparently driven by the incidence of financial crises. More recently, Demetriades and Rousseau (2011) have found that banking supervision has become a more important indicator of the financial development that matters for growth. Their interpretation that 
TABLE 1. OLS growth regressions on access, depth, and efficiency

\begin{tabular}{lcccccc}
\hline & 1 & 2 & 3 & 4 & 5 & 6 \\
\hline Access 1 & 0.71 & 0.74 & 0.74 & - & - & - \\
& $(0.00)$ & $(0.00)$ & $(0.00)$ & & & \\
Access 2 & - & - & - & 0.39 & 0.40 & 0.08 \\
& & & - & $(0.03)$ & $(0.03)$ & $(0.70)$ \\
Depth 1 & 0.26 & - & - & 0.41 & - & - \\
& $(0.59)$ & & $-0.37)$ & & \\
Depth 2 & - & -0.63 & - & - & 0.45 & - \\
& & $(0.60)$ & & & $(0.15)$ & \\
Depth 3 & - & - & 0.18 & - & - & 0.35 \\
& -15.46 & -20.10 & -19.14 & -17.72 & -17.05 & -26.27 \\
Efficiency & $(0.03)$ & $(0.04)$ & $(0.02)$ & $(0.00)$ & $(0.00)$ & $(0.00)$ \\
& 64 & 64 & 53 & 90 & 90 & 77 \\
$n$ & 0.29 & 0.29 & 0.38 & 0.21 & 0.22 & 0.32 \\
$R^{2}$ & & & & & -29 & \\
\hline
\end{tabular}

Note: Numbers in parentheses are robust $p$ values. All variables are averaged over 1987-2008 except access, which is dated around 2004. The dependent variable is the average annual growth rate of real GDP per capita; access 1 is log of commercial bank deposit accounts per 100,000 adults; access 2 is commercial bank branches per 100,000 adults; depth 1 is private credit to GDP; depth 2 is liquid liabilities; depth 3 is stock market capitalization; efficiency is net interest margin; all regressions are conditioned on log GDP in 1987.

the quality of financial development has become more important than the quantity of financial development echoes the theoretical trade-off between efficiency and value added.

The second implication of the model is that financial efficiency and access should be considered alongside a measure of the size of the financial sector in growth regressions. This can be tested using new data on access to financial services in Kendall et al. (2010). Table 1 reports OLS regressions of growth on various measures of access and depth and a measure of efficiency. The dependent variable is the average annual growth rate of real GDP per capita over the period 1987-2008, and all regressions are conditioned on log initial GDP. Data on GDP and growth are from Heston et al. (2011). The access to finance data is from Kendall et al. (2010), and we use the log of the number of commercial bank branches per hundred thousand adults and the log of commercial bank deposit accounts per hundred thousand adults. Financial depth and efficiency data are from Beck et al. (2000). We use three common measures of financial depth: the ratios of private credit, liquid liabilities, and stock market capitalization to GDP. Financial efficiency is measured as the net interest margin (so it has a negative correlation with growth).

As found in other studies that consider a similar time period, such as Rousseau and Wachtel (2011), depth is not statistically significant in any permutation of the reported regressions. Financial efficiency is strongly significant, as would be implied by the theory. In addition, the access variable is statistically significant 
in all but one permutation. The number of commercial bank deposit accounts per 100,000 adults is always strongly statistically significant. The number of commercial bank branches per 100,000 adults is statistically significant in two of the three permutations. Although these results are only indicative correlations, they suggest that access could have an important role in explaining variations in growth. Even where the size of the financial sector is not significant, as in these regressions, incorporating efficiency and access in addition to a measure of depth adds to our understanding of what forms of financial development can contribute to long-run growth. Further research to identify causality requires additional data. $^{12}$

\section{CONCLUDING REMARKS}

This paper has developed an endogenous growth model incorporating access to financial services as well as financial efficiency. The model suggests that our attention should be concentrated on those aspects of financial development that are more fundamentally growth-promoting as opposed to the measures of the size of the financial sector. Although theoretical studies on finance and growth have not generally used depth or value added to proxy for financial development, empirical studies have used depth to identify the nexus in the data. By drawing out the theoretical implications for value added, we have seen why empirical estimates on the relationship between value added (or depth) and growth can be unreliable. A focus on the quality of financial intermediation, rather than its quantity, appears key.

There are a number of potential extensions to this paper. The conception of financial efficiency could be expanded beyond simply the cost of screening entrepreneurs. This would have implications for the implied relationship between efficiency and value added if lower transaction costs or greater risk sharing were related to higher growth via the size of the financial system, as in Acemoglu and Zilibotti (1997). Further, the connections between efficiency and access could be explored in a model where access was endogenous to the costs of using financial services. Finally, it would be interesting to consider a model with capital. The Uzawa (1961) theorem holds that, along a BGP, all technological change must be labor-augmenting. Making a distinction between financial intermediations that separately benefit the discovery of capital- and labor-augmenting technologies would be a direction for future theoretical and empirical research. Models in which the direction of financial innovation matters could follow from work such as Laeven et al. (2009) in which financial development itself is endogenous, and might lead to a richer understanding of the nature of financial development in economies that go through a period of takeoff in long-run growth.

The implications for empirical research have been discussed. Measures of the size of the financial sector appear unreliable as growth determinants. The importance of access in explaining a positive correlation between efficiency and value added suggests ways to approach the empirical estimation of the finance-growth 
nexus, with a particular focus on the importance and determinants of access to finance. Data such as those of Kendall et al. (2010) are well placed to enable such research.

\section{NOTES}

1. See Levine (2005) and Beck (2008) for surveys.

2. See Capasso (2004) for a survey of the theoretical literature.

3. Thus the total size of the financial sector is $D\left(\zeta_{t}\right) Y_{t}$, which can grow as the economy grows. We could otherwise have let the absolute size of the financial sector be some $\mathcal{F}\left(\zeta_{t}\right)$ and then have financial value added as $D\left(\zeta_{t}\right)=\mathcal{F}\left(\zeta_{t}\right) / Y_{t}$.

4. See also Jones and Scrimgeour (2008).

5. Consider the screening of entrepreneurial type in King and Levine (1993b) and Morales (2003) and the monitoring of effort in de la Fuente and Marín (1996) and Blackburn and Hung (1998).

6. We also assume that the information from screening is public (so incapable scientists receive no compensation) but that households represent a diversified pool of scientists. This is in the spirit of the original King and Levine (1993b) model.

7. We are restricting ourselves throughout to equilibria where $\left[1-f\left(\zeta_{t}\right)\right]>\phi$, i.e., where screening is always better than not screening. The results that follow are not sensitive to the way in which the financial cost enters here. We could equally specify $\dot{N}_{t}=\eta_{N}\left[Z_{t}-f\left(\zeta_{t}\right)\right]$ and balanced growth implications for financial value added would remain the same (though with a different implied cost structure for intermediation) and the economy-wide resource constraint would include $f$ separately from $Z$; see endnote 8 .

8. If we had assumed $\dot{N}_{t}=\eta_{N}\left[Z_{t}-f\left(\zeta_{t}\right)\right]$, then $f$ would be the total fee for intermediation and value added would be $\mathcal{D}_{t}=f\left(\zeta_{t}\right) / Y_{t}=z\left(\zeta_{t}\right) /\left(\phi Y_{t}\right)$ because now $f^{*}=z\left(\zeta_{t}\right) / \phi$. Balanced growth again requires that financial costs $z\left(\zeta_{t}\right)$ be proportional to $Z$ along a BGP and so value added is constant.

9. Even in models where financial innovation is endogenous, average financial efficiency is constant along the BGP. In Laeven et al. (2009), aggregate financial efficiency is constant in the steady state, whereas for Greenwood et al. (2010), relative financial efficiency (and proportion of resources allocated to monitoring) is constant along a BGP.

10. For a given amount of research funding to allocate, the higher $\lambda_{t}$, the more screening the intermediary is required to do.

11. The concept of financial sector size used in the model is the contribution of the financial sector to total output, whereas in the data it is financial depth. The former clearly has to be less than one, but the latter can be larger. Ideally, we would have measures of the contribution of the financial sector to output for a large range of countries over a substantial period of time, but, at present, this is only available for OECD countries. For the OECD countries, we can use data from the STAN Structural Analysis Database, OECD (2010). The most relevant measure of value added relative to total economy is for finance, insurance, real estate, and business services as a whole. For the period we study in the following (1987-2008), the correlation coefficients between average value added and standard concepts of financial depth are quite high: for liquid liabilities to GDP ratio, 0.61; for stock market capitalization, 0.58; for bank deposits, 0.63 ; and for private credit, 0.40 . As such, we use depth as a proxy for the value added concept in the theory.

12. Particularly because here access is only available widely around the end of the period over which we average other variables.

\section{REFERENCES}

Acemoglu, Daron (2009) Introduction to Modern Economic Growth. Princeton, NJ: Princeton University Press. 
Acemoglu, Daron and Fabrizio Zilibotti (1997) Was Prometheus unbound by chance? Risk, diversification and growth. Journal of Political Economy 105(5), 709-751.

Aghion, Philippe, Peter Howitt, and David Mayer-Foulkes (2005) The effect of financial development on convergence: Theory and evidence. Quarterly Journal of Economics 120(1), 173-222.

Beck, Thorsten (2008) The econometrics of finance and growth. In Terence C. Mills and Kerry Patterson (eds.), Palgrave Handbook of Econometrics, vol. 2, pp. 1180-1211. New York: Palgrave Macmillan.

Beck, Thorsten and Asil Demirgüç-Kunt (2008) Access to finance: An unfinished agenda. World Bank Economic Review 22(3), 383-396.

Beck, Thorsten, Asil Demirgüç-Kunt, and Ross Levine (2000) A new database on the structure and development of the financial sector. World Bank Economic Review 14(3), 597-605. May 2009 revision. The dataset is updated at the World Bank Finance Research Web site, http://econ.worldbank.org/.

Blackburn, Keith and Victor T.Y. Hung (1998) A theory of growth, financial development and trade. Economica 65(1), 107-124.

Capasso, Salvatore (2004) Financial markets, development and growth: Tales of information asymmetry. Journal of Economic Surveys 18(3), 267-92.

De la Fuente, Angel and Jose M. Marín (1996) Innovation, bank monitoring, and endogenous financial development. Journal of Monetary Economics 38(1), 269-301.

Demetriades, Panicos O. and Khaled A. Hussein (1996) Does financial development cause economic growth? Time-series evidence from 16 countries. Journal of Development Economics 51(2), 387411.

Demetriades, Panicos O. and Peter L. Rousseau (2011) The Changing Face of Financial Development. Mimeo, University of Leicester.

Demirgüç-Kunt, Asli and Vojislav Maksimovic (1998) Law, finance and firm growth. Journal of Finance 53, 2207-2237.

Greenwood, Jeremy and Boyan Jovanovic (1990) Financial development, growth and the distribution of income. Journal of Political Economy 98(5), 1076-1107.

Greenwood, Jeremy, Juan M. Sanchez, and Cheng Wang (2010) Financing development: The role of information costs. American Economic Review 100, 1875-1891.

Hasan, Iftekhar, Michael Koetter, and Michael Wedow (2009) Regional growth and finance in Europe: Is there a quality effect of bank efficiency? Journal of Banking and Finance 33, 1446-1453.

Heston, Alan, Robert Summers, and Bettina Aten (2011) Penn World Table Version 7.0. Center for International Comparisons of Production, Income and Prices at the University of Pennsylvania.

Horii, Ryo, Ryoji Ohdoi, and Kazuhiro Yamamoto (in press) Financial infrastructure, technological shift, and inequality in economic development. Macroeconomic Dynamics.

Jones, Charles I. and Dean Scrimgeour (2008) A new proof of Uzawa's steady-state growth theorem. Review of Economics and Statistics 90(1), 180-182.

Kendall, Jake, Nataliya Mylenko, and Alejandro Ponce (2010) Measuring Financial Access around the World. Policy research working paper 5253, The World Bank.

Khan, Aubhik (2001) Financial development and economic growth. Macroeconomic Dynamics 5(3), 413-433.

King, Robert G. and Ross Levine (1993a) Finance and growth: Schumpeter might be right. Quarterly Journal of Economics 108(3), 717-737.

King, Robert G. and Ross Levine (1993b) Finance, entrepreneurship, and growth: Theory and evidence. Journal of Monetary Economics 32(3), 513-542.

Laeven, Luc, Ross Levine, and Stelios Michalopoulos (2009) Financial Innovation and Endogenous Growth. NBER working paper 15356.

Levine, Ross (2005) Finance and growth: Theory, mechanisms and evidence. In P. Aghion and S.N. Durlauf (eds.), Handbook of Economic Growth, pp. 865-934. Amsterdam: Elsevier.

Levine, Ross, Norman Loayza, and Thorsten Beck (2000) Financial intermediation and growth: Causality and causes. Journal of Monetary Economics 46(1), 31-77.

Morales, Maria F. (2003) Financial intermediation in a model of growth through creative destruction. Macroeconomic Dynamics 7(3), 363-393. 
OECD (2010) Structural Analysis. 2010 ed. ESDS International, University of Manchester. DOI: $10.5257 / \mathrm{oecd} / \mathrm{stan} / 2010$.

Rioja, Felix and Neven Valev (2004) Does one size fit all? A reexamination of the finance and growth relationship. Journal of Development Economics 74(2), 429-447.

Rousseau, Peter L. (1998) The permanent effects of innovation on financial depth: Theory and US historical evidence from unobservable components models. Journal of Monetary Economics 42(2), 387-425.

Rousseau, Peter L. and Richard Sylla (2005) Emerging financial markets and early US growth. Explorations in Economic History 42(1), 1-26.

Rousseau, Peter L. and Paul Wachtel (2011) What is happening to the impact of financial deepening on economic growth. Economic Inquiry 49(1), 276-288.

Schlicht, Ekkehart (2006) A variant of Uzawa's theorem. Economics Bulletin 5(6), 1-5.

Townsend, Robert M. (1983) Financial structure and economic activity. American Economic Review 73(5), 895-911.

Uzawa, Hirofumi (1961) Neutral inventions and the stability of growth equilibrium. Review of Economic Studies 28(2), 117-124. 